\title{
REFLEXOS DAS NORMATIVAS LEGAIS SOBRE FORMAÇÃO DE PROFESSORES DA EDUCAÇÃO BÁSICA EM CONFIGURAÇÕES CURRICULARES DE CURSOS DE LICENCIATURA EM QUÍMICA E FORMAÇÃO DA IDENTIDADE PROFISSIONAL DOCENTE ${ }^{1}$
}

\author{
Edna Falcão Dutra* \\ Eduardo A. Terrazzan**
}

RESUMO: O projeto de pesquisa DIPIED tem desenvolvido o estudo das reformulações em cursos de licenciatura (CL), procurando contribuir para compreensão da organização das configurações curriculares desses cursos. Neste trabalho, tomamos por base CL em Química de sete instituições de ensino superior, UEM, UESC, UFAL, UFSCar, UFSM, UFSJ e URI, para analisar possibilidades das suas configurações curriculares favorecerem a formação identitária do professor. Como fontes de informação, utilizamos projetos político-pedagógicos (PPP) desses cursos. Constatamos que há algumas limitações para formação de identidade profissional que diferencie o professor da Educação Básica do bacharel atuante na área correspondente. De modo geral, os perfis profissionais expressos nesses PPPs contêm elementos favoráveis à estruturação de processos formativos que contribuam para formação da identidade profissional do professor.

Palavras-chave: formação de professores, cursos de licenciatura, projeto políticopedagógico

\section{CONSEQUENCES OF THE LEGAL TERMS ON TEACHER EDUCATION OF THE ELE- MENTARY AND HIGH SCHOOL IN CURRICULAR CONFIGURATIONS OF TEACHER EDUCATION UNDERGRADUATE PROGRAMS IN CHEMISTRY AND TEACHER IDEN- TITY FORMATION}

ABSTRACT: DIPIED research project has developed, as one of its activities, the study of recent reformulations carried out in Undergraduate Teacher Education Programs, seeking to contribute for comprehension of their curricular configuration. In this paper, we took as base the Undergraduate Teacher Education Programs in Chemistry from five Institutions of Higher Education, UEM, UESC, UFAL, UFSCar, UFSM, UFS and URI, to analyze how curricular configurations affect teacher identity formation. As sources of information, we used Political-Pedagogic Project of these programs. We pointed out that, there are still some limitations for the formation of a professional identity that differentiates the teacher of basic education of an operating bachelor in the area of the corresponding knowledge. However, on the whole, the express professional profiles in the PPP of these courses contain favorable elements to the structuring of formative processes that contribute to formation of the professional identity of a teacher.

Keywords: Teacher Education Undergraduate Programs, Curricular Configurations, Professional Identity of the teacher. 


\section{INTRODUÇÃO}

Este trabalho faz parte das atividades do projeto de pesquisa DIPIED "Dilemas e Perspectivas para a Inovação Educacional na Educação Básica e na Formação de Professores", que tem como um de seus objetivos a sinalização de condicionantes para a implementação de inovações em cursos de licenciatura que articulem o atendimento a necessidades de diferentes ordens, tais como legislação vigente, características de agências formadoras e necessidades dos sistemas de ensino, com particular atenção à organização e ao desenvolvimento das Práticas como Componente Curricular (PCCs) e dos Estágios Curriculares Pré-Profissionais (ECPPs) previstos nas normativas legais.

Uma das ações investigativas desse projeto visa a contribuir para uma melhor compreensão da organização das atuais configurações curriculares de cursos de licenciatura de instituições de ensino superior do país, a partir das normativas legais em vigor. Para isso, uma das etapas dessa ação é a análise da documentação disponível desses cursos. A outra etapa refere-se à observação de algumas realidades de forma mais próxima e ao acompanhamento do desenvolvimento local de algumas atividades relativas a esses cursos.

Neste texto, discutimos os reflexos das normativas legais sobre a formação de professores para a educação básica e sobre os cursos de Química nas configurações curriculares de cursos de licenciatura em Química de sete instituições de ensino superior: Universidade Estadual de Maringá (UEM); Universidade Estadual de Santa Cruz (UESC); Universidade Federal de Alagoas (UFAL); Universidade Federal de Santa Maria (UFSM); Universidade Federal de São Carlos (UFSCar); Universidade Federal de São João del-Rei (UFSJ) e Universidade Regional Integrada do Alto Uruguai e das Missões (URI). Procuramos evidenciar e caracterizar elementos presentes nas configurações curriculares desses cursos que possam favorecer a formação identitária do professor de Química.

A formação de professores a partir das atuais normativas legais é um tema bastante debatido em eventos da área, pois se acredita que essas normativas trouxeram mudanças na organização dos cursos de licenciatura, fazendo com que os responsáveis por eles, coordenadores de cursos, professores formadores, licenciandos, refletissem sobre o real papel da licenciatura dentro das instituições formadoras. No entanto, para estudarmos as atuais configurações curriculares e entendermos as propostas das normativas legais vigentes, consideramos interessante retomar brevemente alguns aspectos das reformulações curriculares nos cursos de formação de professores ocorridas no Brasil.

Na década de 1970, a ênfase na formação docente estava em uma formação técnica, afetando diretamente a prática dos professores, que se reduzia em definição de objetivos e metas, seleção e desenvolvimento de conteúdos e avaliação da aprendizagem. Nesse período, o professor era formado para fazer uso de 
Reflexos das normativas legais sobre formação de professores da educação básica em configurações curriculares de cursos de licenciatura em química e formação da identidade profissional docente

técnicas pré-estabelecidas e devidamente ajustadas para um determinado fim.

Nessa época, surgiu das discussões e produções da área um movimento de oposição ao caráter funcional dado às licenciaturas. Isso fortaleceu, nos anos 1980, a busca por estudos sobre uma educação voltada às questões sociais e políticas. Os educadores assumiram um compromisso com as classes populares. Os objetivos educacionais passaram a ser novamente discutidos, e a formação de professores despontou como um problema diretamente relacionado à realidade brasileira. Esse período também foi marcado pela insatisfação com o caráter tecnicista e aplicacionista, reguladores das práticas desenvolvidas nos cursos de formação de professores até então. Esse modelo de formação de professores ficou conhecido como modelo da racionalidade técnica, no qual, conforme Pereira (1999), o professor é visto como "um técnico, um especialista que aplica com rigor, na sua prática cotidiana, as regras que derivam do conhecimento científico e do conhecimento pedagógico".

Nos anos 1990, iniciou-se uma grande reforma na educação brasileira. Os elementos centrais dessa reforma evidenciam que o processo de profissionalização é baseado nos conceitos e nas práticas oriundas do campo do trabalho docente. Essa reforma chegou aos anos 2000 a partir dos documentos e atos normativos que determinam o quadro oficial, estabelecendo uma nova configuração para a formação inicial de professores.

Essa nova configuração é baseada em outro modelo de formação de professores, que procura se contrapor ao anterior: o modelo da racionalidade prática, no qual o professor é considerado um profissional autônomo, que reflete, toma decisões e cria durante sua ação pedagógica. De acordo com essa concepção, a prática não é apenas o momento da aplicação de um conhecimento científico e pedagógico, mas espaço de criação e de reflexão, em que novos conhecimentos são, constantemente, gerados e modificados. Nas normativas legais para a formação inicial de professores, em especial, no que se refere à organização e à operacionalização das configurações curriculares, notamos a presença de algumas características que vão ao encontro desse modelo, como o fato de o profissional ser instigado a refletir constantemente sobre sua própria prática.

Um dos componentes curriculares de cursos de licenciatura investigados neste trabalho foi o conjunto de disciplinas dedicadas, parcial ou integralmente, à PCC, considerado por Fernandes (2008) como um grande impacto trazido pela legislação recente, pois incide diretamente sobre a formação de professores, buscando-se a articulação entre a teoria e a prática e exigindo-se uma visão de curso em suas várias dimensões. No Parecer CNE/CP 9/2001, afirma-se que conceber a prática como um componente curricular implica considerá-la "uma dimensão do conhecimento que está presente nos cursos de formação de professores nos momentos em que se trabalha na reflexão sobre a atividade profissional". Nesse sentido, para auxiliar o atendimento a um dos objetivos da formação de profes- 
sores, que é fazer com que o futuro professor vivencie a realidade escolar, a prática deve

"começar da totalidade que é escola, conhecê-la no seu contexto, para depois separar e isolar este conhecimento nos diferentes componentes [curriculares], o que abarcaria e incluiria todas as disciplinas". (PIMENTA, 1995, p.70)

Assim, no caso das disciplinas que tratam de conhecimentos "específicos da matéria de ensino" e que terão parte da carga horária dedicada à PCC, essas deverão proporcionar a reflexão sobre esses conhecimentos que estão sendo aprendidos pelo licenciando e que, após um processo de transposição didática, serão por eles ensinados durante a sua atuação profissional como professores.

Outro componente curricular analisado foi o conjunto de disciplinas dedicadas ao ECPP. Tradicionalmente, a formação de professores utilizou-se sempre de estágios curriculares (EC) para complementar o currículo de formação de docentes, sendo eles vistos na dimensão experimental; assim, aprendia-se primeiro a teoria para depois se colocá-la em prática. Essa fórmula, embora desgastada, continua a fundamentar alguns cursos de formação de professores. De acordo com o Parecer CNE/CP 21/2001 (BRASIL, 2001), o ECPP deve ser encarado como "um momento de formação profissional do formando seja pelo exercício in loco, seja pela presença participativa em ambientes próprios de atividades daquela área profissional, sob a responsabilidade de um profissional já habilitado", no qual o futuro profissional possa ter contato direto com o trabalho docente. (grifo nosso). Essa ideia é reiterada por Kulcsar (2003) ao afirmar que o EC deve ser considerado um instrumento fundamental no processo de formação do professor, auxiliando o aluno em situação de estágio a compreender e a enfrentar o mundo do trabalho e contribuindo para a formação de sua consciência político-social.

Um terceiro componente curricular relevante à formação docente é o conjunto de disciplinas que auxiliam na formação do conhecimento pedagógico. De acordo com Shulman (1987), esse conhecimento transcende a especificidade de uma área disciplinar do saber. Abrange o conjunto dos conhecimentos próprios de qualquer profissional do ensino, independentemente da área disciplinar ou nível de escolaridade em que atue. São esses conhecimentos que garantem a especificidade da profissão docente. Podem-se incluir nesse conjunto os conhecimentos relativos ao currículo, aos contextos educacionais, aos fins, aos propósitos e aos valores educacionais, aos alunos e a suas características e às teorias e aos princípios próprios aos processos de ensinar e de aprender. Essa relevância atribuída ao conhecimento pedagógico também está presente na Resolução 1/2002, que estabelece que o tempo dedicado às dimensões pedagógicas, nos cursos de licenciatura, não deverá ser inferior a quinta parte da carga horária total (Art. 11, parágrafo único).

Para relacionarmos a forma como os componentes curriculares estudados estão organizados nesses cursos com a formação da identidade profissional 
Reflexos das normativas legais sobre formação de professores da educação básica em configurações curriculares de cursos de licenciatura em química e formação da identidade profissional docente

dos seus licenciados, torna-se necessário apontar alguns fatores que acreditamos fazer parte da formação identitária dos professores. Acreditamos que a identidade profissional de professores é resultante de experiências de ensino vivenciadas em diferentes espaços com diferentes sujeitos, de escolhas realizadas por esse profissional, da relação que ele mantém com sua formação e do sentido que ele confere ao seu trabalho (DUBAR, 1997). Consideramos que esses fatores estão presentes tanto na formação inicial quanto na continuada. Por isso, a formação da identidade profissional se dá mediante um processo de construção e reconstrução constante.

Neste trabalho, optamos por centrar nossa atenção na análise dos componentes curriculares já mencionados, tais como se apresentam e se articulam nas propostas de cursos de licenciatura em Química de diferentes instituições de ensino superior (IES), por considerarmos ser possível, desse modo, identificar e discutir aspectos que possam favorecer a formação identitária dos licenciados nesses cursos.

\section{DESENVOLVIMENTO DO TRABALHO}

Este trabalho foi desenvolvido a partir de uma pesquisa documental. A concepção que adotamos referente ao termo "documento" vai ao encontro da concepção de Chizzotti (2000, p.109):

\footnotetext{
"qualquer informação sob a forma de textos, imagens, sons, sinais, etc., contida em um suporte material (papel, madeira, tecido, pedra), fixados por técnicas especiais como impressão, gravação, pintura, incrustação, etc. Quaisquer informações orais (diálogo, exposição, aula, reportagens faladas) tornam-se documentos quando transcritos em suporte material".
}

Desse modo, para o autor, a pesquisa documental é parte integrante de qualquer pesquisa sistemática e precede ou acompanha os trabalhos de campo. Ela pode ser um aspecto dominante em trabalhos que visam a mostrar a situação atual de um determinado assunto ou intentam traçar a evolução histórica de um problema.

Como fontes documentais, tomaram-se os PPPs dos cursos de licenciatura em Química já mencionados. Para análise dessa documentação, elaboramos um roteiro para leitura e análise textual desses PPPs. Um roteiro desse tipo pressupõe questões a serem respondidas mediante a leitura crítica de um documento, de tópicos que nele se desejam encontrar e a partir dos quais se orienta uma leitura exploratória. Os roteiros de análise devem ajudar o pesquisador a localizar informações relevantes em meio a um conjunto extenso e/ou amplo de informações variadas.

Para desenvolvermos essa pesquisa, traçamos o seguinte percurso: 1) recolha dos PPPs de um conjunto de cursos de licenciatura em Química mediante acesso ao site de cada IES; 2) elaboração de roteiro para coleta de informações baseado nas propostas das normativas legais para formação de professores para a 
educação básica; 3) leitura desses mesmos PPPs, a partir de roteiro pré-estabelecido; 4) organização e tratamento das informações coletadas; 5) construção e interpretação dos resultados.

\section{RESULTADOS E CONSTATAÇÕES}

\section{Organização das disciplinas dedicadas parcial ou integramente à PCC}

Constatamos que os sete cursos investigados estão formalmente em consonância com os atos normativos vigentes para a formação de professores, no que diz respeito à PCC, pois eles apresentam carga horária destinada às atividades de práticas referentes à docência pouco superior às 400 horas exigidas, sendo essas distribuídas ao longo da formação e não ficando restritas apenas aos momentos de desenvolvimento do EC. Do ponto de vista formal, no curso de Licenciatura em Química oferecido pela URI, todas as disciplinas dedicadas à PCC (16) estão organizadas de modo que uma parte da carga horária é destinada à aprendizagem de conhecimentos teóricos e outra parte à aprendizagem dos chamados conhecimentos práticos. O mesmo acontece no curso oferecido pela UEM, no qual todas as oito disciplinas têm uma parte da carga horária destinada à aprendizagem de conhecimentos teóricos e outra parte à aprendizagem de conhecimentos práticos. No curso oferecido pela UESC, a maioria das disciplinas (24) também está organizada dessa forma, com exceção de uma disciplina (O professor e o ensino de Química), que possui a carga horária totalmente dedicada à aprendizagem de conhecimentos práticos. O mesmo ocorre no curso oferecido pela UFSM, no qual a maioria das disciplinas (15) tem uma parte da carga horária destinada à aprendizagem de conhecimentos teóricos e outra parte à aprendizagem de conhecimentos práticos, com exceção de uma disciplina (Instrumentação para Laboratório de Química) que possui a carga horária totalmente dedicada à aprendizagem de conhecimentos práticos. No curso oferecido pela UFAL, há 13 disciplinas que dedicam parte da parte da carga horária à aprendizagem de conhecimentos teóricos e outra parte à aprendizagem de conhecimentos práticos e sete disciplinas que se dedicam totalmente a aprendizagem de conhecimentos práticos. Nessas sete disciplinas, denominadas "projetos integradores", é previsto que haja uma interação entre as diferentes disciplinas oferecidas durante os semestres letivos, de modo que elas reflitam na atuação do futuro professor na educação básica. No curso oferecido pela UFSCar a maioria das disciplinas (06) está organizada de modo que toda a carga horária seja destinada ao trabalho com conhecimentos práticos, com exceção de duas disciplinas (Metodologia do Ensino de Química 1 e 2), que destinam parte da carga horária também para a aprendizagem de conhecimentos teóricos. No curso oferecido pela UFSJ, todas as disciplinas (09) estão organizadas de modo que a carga horária delas esteja totalmente voltadas para a aprendizagem de conheci- 
Reflexos das normativas legais sobre formação de professores da educação básica em configurações curriculares de cursos de licenciatura em química e formação da identidade profissional docente

mentos práticos. Grande parte das ementas das disciplinas que compõem o componente curricular PCC refere-se às atividades que o graduando poderá vivenciar ao longo da profissão, como o planejamento de atividades teórico/práticas a partir de conteúdos estudados a serem desenvolvidas no ensino básico.

\section{Organização das disciplinas referentes aos EC}

Constatamos que quatro cursos apresentam uma carga horária pouco superior às 400 horas previstas legalmente para as atividades de EC e dão início a essas atividades a partir da segunda metade do curso, estando, em uma primeira análise, em acordo com as Resoluções CNE/CP 1/2002 e 2/2002. Em cinco dos sete cursos analisados, as disciplinas de EC iniciam no quinto semestre (num total de oito semestres), ou seja, a partir da segunda metade do curso, como no caso da UEM, UESC, UFAL, UFSM e da UFSJ. No curso de Licenciatura em Química oferecido pela URI, o EC tem início no sexto semestre (num total de nove semestres). O curso oferecido pela UFSCar realiza o EC apenas no último ano do curso, ou seja, no nono e no décimo semestres. Os cursos oferecidos pela UESC, UFAL, UFSM e pela URI preveem a atuação do estagiário no ensino fundamental, além da tradicional intervenção no ensino médio prevista nos cursos oferecidos pela UEM, UFSJ e pela UFSCar. Os cursos oferecidos pela UFSM e pela URI também sugerem, como possíveis campos de estágio, alguns espaços diferentes do ambiente escolar típico, o que não é previsto nas normativas legais para formação de professores em relação ao EC formal. Quanto às atividades previstas para serem realizadas em cada uma das disciplinas de estágio, elas contemplam, entre outras tarefas: observação e análise tanto da estrutura e dos mecanismos de funcionamento da escola como das dinâmicas em sala de aula; planejamento, avaliação e reformulação das atividades desenvolvidas em escolas de educação básica. A avaliação do desempenho do estagiário é, em geral, realizada mediante a entrega e a apresentação de relatório descritivo das atividades de ECPP desenvolvidas por ele. Com relação ao acompanhamento do desenvolvimento dos estagiários, nenhum dos cursos analisados define claramente como será realizado e qual a função dos envolvidos nesse processo (escola, professor orientador de estágio da IES, estagiário de Curso de Licenciatura e professor regente de turma da escola campo de estágio). Nos cursos analisados não foi encontrada uma orientação sobre mecanismos que operacionalizem a interação entre Universidade-Escola.

\section{Organização das disciplinas referentes à formação pedagógica}

Constatamos que os cursos analisados destinam uma carga horária consideravelmente elevada para a formação pedagógica de seus licenciandos. Para abordar a formação pedagógica dos licenciandos a dividimos em dois tipos: for- 
mação pedagógica geral - formação que todo professor deve ter, independentemente da área disciplinar que atua - e formação pedagógica específica - formação que o professor de Química deve ter, com o conhecimento de todas as particularidades que essa área disciplinar apresenta. Além disso, os cursos incorporaram em seus currículos disciplinas diferentes daquelas previstas pelo antigo currículo mínimo de formação de professores. Esse currículo mínimo foi proposto pelo Parecer CFE 292/62 e orientava para que 1/8 da carga horária total do curso fosse dedicada à formação pedagógica, sendo que faziam parte dessa formação apenas as disciplinas de Psicologia da Educação, de Didática e de Estrutura e Funcionamento de Ensino de $1^{\circ}$ e $2^{\circ}$ graus.

A formação pedagógica no curso ofertado pela UFSM está organizada em nove disciplinas, sendo que cinco tratam da formação pedagógica geral e quatro da formação pedagógica específica do professor de Química, contabilizandose 630 horas. Isso representa cerca 19\% da carga horária total do curso. No curso oferecido pela UEM, são oferecidas seis disciplinas para a formação pedagógica de seus alunos, sendo três para a formação pedagógica geral e três para a formação pedagógica específica do professor de Química, contabilizando-se 374 horas, cerca de $11 \%$ da carga horária total do curso. O curso oferecido pela UESC possui dez disciplinas destinadas à formação pedagógica, sendo seis para a formação pedagógica geral e quatro para a formação pedagógica específica, contabilizando-se 570 horas. Isso representa cerca de $18 \%$ da carga horária total. No curso oferecido pela UFAL são oferecidas oito disciplinas para a formação pedagógica de seus alunos, sendo sete para a formação pedagógica geral e apenas uma para a formação pedagógica específica do professor de Química, contabilizando-se 440 horas, cerca $14 \%$ da carga horária total do curso. O curso oferecido pela URI possui onze disciplinas destinadas à formação pedagógica, sendo sete para a formação pedagógica geral e quatro para a formação pedagógica específica, contabilizando-se 450 horas. Isso representa cerca de $15 \%$ da carga horária total. No curso da UFSJ são oferecidas nove disciplinas para a formação pedagógica de seus licenciandos, sendo duas para a formação pedagógica geral e sete para a formação pedagógica específica. O curso destina 420 horas para a formação pedagógica, ou seja, cerca de $15 \%$ da carga horária total do curso. No curso da UFSCar todas as sete disciplinas de formação pedagógica tratam de assuntos específicos da formação do professor de Química, contabilizando-se 360 horas de formação pedagógica, o que representa cerca de 12\% da carga horária total do curso. Em geral, nos cursos analisados, a formação pedagógica dos licenciandos está distribuída ao longo dos semestres, permeando toda a sua formação.

\section{Formação identitária do professor}

Os cursos de licenciatura em Química analisados, com exceção do curso 
Reflexos das normativas legais sobre formação de professores da educação básica em configurações curriculares de cursos de licenciatura em química e formação da identidade profissional docente

oferecido pela UEM, possuem um PPP específico diferente do PPP do respectivo curso de bacharelado, sendo que o ingresso em cada um deles se dá de forma separada. Os objetivos do curso da UFSM estão diretamente voltados à formação de professores de Química aptos a exercer a função docente e com amplo domínio dos conhecimentos relacionados a essa função. Além disso, é prevista a oferta de mecanismos para a qualificação profissional mediante a iniciação è pesquisa em educação e em educação em química durante o curso. O curso da URI almeja formar profissionais para atender à demanda de atuação no campo educacional e também para desenvolver pesquisas que atendam o campo social e industrial, nas suas diferentes áreas. Na UEM, UESC, UFAL e UFSJ, os objetivos do curso se referem à formação de professores de Química para atuar na educação básica. A UEM e a UFSCar deseja que os licenciados em Química sejam profissionais críticos em relação a sua atuação profissional e se tornem pesquisadores capazes de dominar os conhecimentos químicos e pedagógicos e de refletirem sobre o seu papel na sociedade. No perfil esperado para um licenciado em Química pela UFSM, encontramos algumas características específicas relacionadas à atuação pedagógica, a saber: 1) "[...] ser um profissional consciente de seu papel de educador, contribuindo, assim, para o desenvolvimento da consciência crítica, no âmbito do ensino médio e fundamental"; 2) "ter capacidade crítica para analisar de maneira conveniente os seus próprios conhecimentos [...]". Os perfis profissionais almejados pela UESC, UFAL, UFSJ e pela URI retomam o que está previsto nas normativas legais referentes aos cursos de Química (Parecer CNE/CES 1.303/2001 e Resolução CNE/CES 8/2002), ou seja, o licenciado deve ter, entre diversas habilidades, um "sólido conhecimento acerca da teoria e dos métodos práticos que se fazem presentes no processo de ensino-aprendizagem da química [...]". A UFS Car espera que seu licenciado em Química também exerça suas atividades em espaços de ensino não formal, até agora pouco explorado, como ensino à distância, educação especial. Esse curso também sugere que o licenciado continue sua formação acadêmica ingressando preferencialmente na pós-graduação nas áreas de Ensino de Química, Educação, Divulgação Científica ou qualquer das subáreas da Química.

\section{CONSIDERAÇÕES FINAIS}

A Resolução CNE/CP 1/2002, em seu artigo 12, parágrafo $3^{\circ}$, prevê que "no interior das áreas ou das disciplinas que constituírem os componentes curriculares de formação, e não apenas nas disciplinas pedagógicas, todas terão a sua dimensão prática". Dessa forma, consideramos positivo o fato de alguns cursos terem incorporado também disciplinas correspondentes à respectiva matéria de ensino na educação básica. Assim sendo, é provável que a visão dos licenciados desses cursos sobre os possíveis espaços e atividades que serão vivenciados na 
futura profissão não fique restrita à formação pedagógica geral, pois eles também terão a possibilidade de desenvolver atividades que possibilitem a mobilização do "conhecimento pedagógico do conteúdo" relativos a sua área disciplinar de ensino. No entanto, para que isso ocorra é necessário o compromisso dos professores formadores com o desenvolvimento das atividades práticas propostas e com os objetivos estabelecidos para a formação profissional dos futuros professores da educação básica. O fato de as atividades de PCC estarem distribuídas ao longo dos cursos, atendendo às determinações das atuais normativas legais, poderá levar o licenciando a preocupar-se mais com sua prática docente e com as questões relativas a sua futura profissão, o que lhe poderá proporcionar o contato com os diversos aspectos da ação docente desde seu ingresso no curso, além de propiciar o desenvolvimento da uma prática reflexiva e a construção do seu próprio conhecimento empírico, favorecendo, assim, a sua identificação com a profissão docente.

Um fato que merece destaque é a abertura do campo de estágio para o ensino fundamental, visto que essa não é uma prática usual nesses cursos, ampliando-se assim a possibilidade de atuação do profissional formado por esee curso na educação básica, o que de certa forma é uma oportunidade de atenuar a tradição da reserva de vagas no mercado educacional aos profissionais da área de ensino de Biologia.

As normativas legais referentes aos cursos de Química orientam para a formação de um licenciado apto a trabalhar a educação em Química tanto no ensino médio quanto no ensino fundamental. Apesar disso, várias IES reformularam seus cursos de Química sem observar essa recomendação. Tradicionalmente, a tarefa de ministrar aulas de Ciências para alunos de $5^{a}$ a $8^{a}$ séries do ensino fundamental, em nosso país, tem sido quase que exclusiva do professor de Biologia. Porém, as orientações dos Parâmetros Curriculares Nacionais e das Diretrizes Curriculares Nacionais para esse nível de ensino definem os mesmos quatro eixos temáticos para serem trabalhados em cada uma dessas quatro séries. Isso pode ser efetivado se houver práticas docentes articuladas e/ou conjuntas entre profissionais das diferentes áreas da Educação em Ciências. Nesse sentido, os cursos que já estão formando profissionais para atuar nesse nível da educação básica encontram-se em uma situação favorável e mais avançada em relação aos demais.

Os cursos da UFSM e da URI também sugerem, como possíveis campos de estágio, alguns espaços diferentes do ambiente escolar típico, o que não é previsto nas normativas legais para formação de professores em relação ao EC formal. Assim, embora essa abertura seja enriquecedora, existem outras formas de se inserir, na organização curricular de um curso de licenciatura, a vivência da docência em outros espaços além da EEB. Do ponto de vista das próprias normativas legais, isso pode ser realizado tanto dentro da carga horária prevista para PCC, como nas 200 horas previstas para as atividades acadêmico-científico-culturais. 
Reflexos das normativas legais sobre formação de professores da educação básica em configurações curriculares de cursos de licenciatura em química e formação da identidade profissional docente

O ECPP é um componente curricular essencial da formação inicial de professores, pois fornece elementos importantes para a formação da identidade profissional do futuro professor. Dessa forma, consideramos que os documentos que orientam a organização dos cursos de licenciatura deveriam contemplar de modo mais claro as atividades a serem desenvolvidas no âmbito das disciplinas referentes a esse componente curricular e indicando as questões profissionais que serão trabalhadas nelas.

A oferta de outras disciplinas de formação pedagógica, além daquelas tradicionalmente ofertadas no antigo currículo mínimo, pode vir a configurar-se como um avanço na organização curricular dos cursos de licenciatura em Química analisados, pois é provável que a visão dos licenciados desses cursos sobre possíveis metodologias de ensino e espaços de ação profissional não fique restrita a um pequeno leque de possibilidades. Além disso, eles também terão a oportunidade, através das disciplinas de formação pedagógica específica, de desenvolver atividades que possibilitem a mobilização do "conhecimento pedagógico do conteúdo" relativos a sua área disciplinar de ensino. Assim, podemos afirmar que os cursos analisados buscaram proporcionar uma formação pedagógica abrangente e aprofundada, o que é consoante com outros resultados obtidos em pesquisas de nosso grupo, os quais indicam ser essa uma preocupação recorrente em diversos cursos de licenciatura em Química, mesmo nas configurações curriculares mais restritas vigentes anteriores à legislação atual. Acreditamos que a mobilização dos conhecimentos "pedagógico geral” e "pedagógico do conteúdo" é uma atividade essencial para a formação de professores, pois permite a distinção entre o professor e o bacharel, por exemplo. Assim, acreditamos que os cursos analisados oferecem uma formação pedagógica favorável à formação identitária de seus futuros professores.

Um último aspecto que analisamos para identificar a possibilidade de os elementos presentes nas configurações curriculares dos cursos de licenciatura em Química analisados favorecerem a formação identitária do professor de Química é a relação entre os objetivos dos cursos e o perfil do egresso. Percebemos que todos os cursos estão preocupados com a formação do professor para a docência no ensino básico, uns em maior e outros em menor grau. Além disso, os cursos apontam outras funções que o professor deve exercer, como a de pesquisador tanto na área da Química como na do ensino. Acreditamos que essa preocupação contribui para a formação identitária de professores, pois orienta o restante do curso a organizar suas configurações curriculares visando essa formação.

A partir da análise da organização e da articulação dos componentes curriculares, percebemos que ainda há sinalizações de um certo interesse pela formação de uma identidade profissional que diferencie o professor da educação básica de um bacharel atuante na área do conhecimento correspondente. Dessa forma, podemos dizer que, de modo geral, os aspectos que auxiliaram na análise desse trabalho 
contêm elementos favoráveis à estruturação de processos formativos que contribuam para formação da identidade profissional de um professor de Química.

\section{BIBLIOGRAFIA}

BRASIL, Ministério da Educação, Conselho Federal de Educação: (1962). Parecer 292/62, de 14 de novembro de 1962 - Fixa a parte pedagógica dos currículos minimos relativos aos cursos de licenciatura. Brasília: Documenta no 10, 10 Dez. 1962, p. 95-100.

: (2001b) Parecer CNE/CP 09, 08 de Maio de 2001 - Diretrizes Curriculares Nacionais para a Formação de Professores da Educação Básica, em nivel superior, curso de licenciatura, de graduação plena. Brasília: Diário Oficial da União, 18 Jan. 2002, Seção 1, p.31. Disponível em: <http://portal.mec.gov.br/cne/ arquivos/pdf/009.pdf>. Acesso em: 18 Fev. 2007.

: (2001c). Parecer CNE/CP 21, 06 de Agosto de 2001 - Duração e carga horária dos cursos de Formação de Professores da Educação Básica, em nivel superior, curso de licenciatura, de graduação plena. Brasília. Disponível em: <http://portal.mec.gov.br/ cne/arquivos/pdf/021. pdf>. Acesso em: 18 Fev. 2007.

: (2002b). Resolução CNE/CP 01, de 18 de Fevereiro de 2002 - Institui Diretrizes Curriculares Nacionais para a Formação de Professores da Educação Básica, em nivel superior, curso de licenciatura, de graduação plena. Brasília: Diário Oficial da União, 09 Abr. 2002, Seção 1, p.31. Disponível em: < http://portal.mec.gov.br/cne/arquivos/pdf /rcp01_02.pdf>. Acesso em: 22 Fev. 2007.

: (2002c) Resolução CNE/CP 02, de 19 de Fevereiro de 2002 - Institui a duração e a carga horária dos cursos de licenciatura, de graduação plena, de formação de professores da Educação Básica em nivel superior. Brasília: Diário Oficial da União, 04 Mar. 2002, Seção 1. p.9. Disponível em: < http://portal.mec.gov.br/cne/arquivos/pdf/CP022002.pdf>. Acesso em: 22 Fev. 2007.

CHIZZOTTI, Antonio. Pesquisa em ciências humanas e sociais. 4.ed. São Paulo/BRA: Cortez. (Coleção "Biblioteca da Educação", Série 1, Escola, 16), 2000.

KULCSAR, Rosa. O estágio supervisionado como atividade integradora. In: Piconez, Stela B. (coord.). A prática de ensino e o estágio supervisionado. 9.ed. (p.38-48). Campinas: Papirus, 2003. PEREIRA, Júlio Emílio Diniz. As licenciaturas e as novas políticas educacionais para a formação docente. Educação e Sociedade. 68, 1999.

PIMENTA, Selma Garrido. O estágio na formação de professores: unidade teoria e prática? 2.ed. São Paulo/BRA: Cortez, 1995.

SHULMAN, Lee S. Knowledge and Teaching: foundations of the new reform. Harvard Educational Review, 57(1), p.1-22, 1987

TERRAZZAN, Eduardo A. et.al. Configurações curriculares em cursos de licenciatura e formação identitária e professores. Revista Diálogo Educacional, 23(8), p. 71-90, 2008.

Data de recebimento: 26/08/2009

Data de aprovação: 03/08/2011

Data da versão final: 16/12/2011 